\title{
Sleep Patterns in Hyperphenylalaninemia: A Lesson on Serotonin to be Learned from Phenylketonuria
}

\author{
F. J. Schulte ${ }^{[75]}$, H. J. Kaiser, S. Engelbart, E. F. Bell, R. Castell, and H. G. Lenard \\ D’epartment of Pediatrics, University of Göttingen, Göttingen, Germany
}

\begin{abstract}
Extract
Sleep behavior and bioelectric brain development have been studied by means of polygraphic recordings (respiration, eye movements, muscle activity, and electroencephalogram (EEG)) in 22 infants and young children with phenylketonuria (PKU). The EEGs were analyzed by a special visual pattern recognition program as well as by means of computer spectral analysis. The distribution between rapid eye movement (REM) or active and non-REM (NREM) or quiet sleep was not found to be different from control infants of the same age. Quite contrary to current theories on the biochemical regulation of sleep as derived from acute animal experiments, our results indicate that, under chronic conditions, a normal sequence of quiet and active sleep can be maintained despite a severe lack of blood and cerebrospinal fluid serotonin as it occurs in hyperphenylalaninemia. In the EEG of subjects with PKU the development of $\sigma$ rhythm or sleep spindle $(12-16 \mathrm{cps})$ activity was enhanced and already abnormal as early as 5 weeks after term birth. The frequency of $\sigma$ waves as well as of hypnagogic, monomorphic, $\theta$ activity was shifted toward higher values. Dietary treatment of 4-6 weeks duration and normalization of blood phenylalanine levels did not significantly change the abnormal bioelectric phenomena.
\end{abstract}

\section{Speculation}

The increase in high frequency regular rhythmic activity in the sleep EEG of subjects with PKU can be explained by decreased concentrations of inhibitory synaptic transmitters such as serotonin and $\gamma$-aminobutyric acid. The developmental course in the expressivity of sleep spindles during the 1st year of life, together with reliable methods of quantified EEG analysis, seems to be a rather sensitive indicator of normal or abnormal brain maturation.

\section{Introduction}

"In the present state of central nervous system science seldom has the proverbial drunk's search for his wallet under the lightpost (instead of where it might be) been better exemplified than in the assignment of determining roles to the biogenic amines in various behavioral states."

Mandell et al. [46]

An interesting aspect of phenylketonuria (PKU) should be, in theory, alterations of sleep behavior because of the disturbances of tryptophan metabolism in this disease. Either the hydroxylation of tryptophan, the active transport of 5-hydroxytryptophan into the brain, or the 5-hydroxytryptophan decarboxylase activity is inhibited [29,61], presumably by the elevated blood levels of phenylalanine and its metabolites [14, 52]. Thereby the amount of blood and cerebrospinal 
fluid 5-hydroxytryptamine (serotonin) $[6,28,62] \gamma$-aminobutyric acid [5] is diminished in PKU. Serotonin has occasionally been labeled "somnotonin" [37] and there is general agreement that it facilitates sleep $[15,38,60$, $70]$.

Jouvet [31, 32] proposes that the raphe nuclei of the brain stem of the cat constitutes a system-a "sleep lobby" - with serotonin as a transmitter, which when activated produces quiet or slow wave or NREM sleep $[10,24,31,40,47,57]$. The locus coeruleus, on the other hand, with norepinephrine as a transmitter, would produce active or paradoxical or REM sleep.

Petre-Quadens and Jouvet [54], as well as Feinberg et al. [20], found abnormal sleep distribution with a trend toward low values for REM in patients with mental retardation from various causes, including a few with PKU. Inasmuch as blood and cerebrospinal fluid serotonin is low in PKU, these results do not support Jouvet's theory on serotonin as a quiet sleep transmitter. However, the experiments of Wyatt et al. $[68,69]$ with parachlorphenylalanine as well as with 5-hydroxytryptophan would lead one to conclude that in man, quite contrary to some experimental animals, serotonin facilitates REM sleep.

If either one of these theories is correct, one should find an abnormal ratio of quiet and active sleep in infants with PKU. Moreover, short term treatment with a low phenylalanine diet should have a normalizing influence on the sleeping patterns of such infants.

\section{Subjects}

Four groups of infants and children were selected for comparison. None of the infants received any medication or tranquilizer for at least 3 days before the EEG recording. None of the infants was on continuous drug therapy.

\section{Group I: Subjects with Untreated PKU}

Twenty-two infants and children between 16 days and 3.75 years of age were selected on the basis of the following findings. The $\mathrm{FeCl}_{3}$ urine test was positive in all subjects. The phenylalanine blood level was persistently greater than $20 \mathrm{mg} / 100 \mathrm{mI}$ in 15 cases. One infant had a phenylalanine level between 15 and 20 $\mathrm{mg} / 100 \mathrm{ml}$ but a sibling was idiotic from untreated classical phenylketonuria. Three untreated children between 1.5 and 4 years of age had phenylalanine blood levels between 8 and $15 \mathrm{mg} / 100 \mathrm{ml}$, but all three had a severe mental defect. Thus, 19 cases were re- garded as classic PKU. In the three remaining cases blood phenylalanine never exceeded $18 \mathrm{mg} / 100 \mathrm{ml}$. On the basis of a persistent phenylalanine level above $8 \mathrm{mg} / 100 \mathrm{ml}$ on a normal protein intake during the 1st year of life they were treated by a diet low in phenylalanine [73]. In retrospect, these three cases have to be regarded as atypical PKU or as long lasting hyperphenylalaninemia. The number of these atypical cases is too small to draw definite conclusions in regard to differences between classic and atypical PKU. However, this will be the main topic of our further studies.

\section{Group II: Control Subjects}

Twenty-two healthy normal infants and children were matched for age with the infants and children of group I.

\section{Group III: Subjects with PKU under Dietary Treat- ment}

Thirteen infants and children between 45 days and 3 years 10 months of age were reinvestigated after. treatment. Before recording they had been under continuous dietary treatment for $10-18$ days in five cases and for $1-11 / 2$ months in eight cases. At the time of recording, the $\mathrm{FeCl}_{3}$ test was negative and the Guthrie test indicated that the serum phenylalanine was below $8 \mathrm{mg} / 100 \mathrm{ml}$. None of these children had convulsions.

\section{Group IV: Selected Subjects with Untreated PKU}

Thirteen infants and children with untreated PKU from group $I$ were matched for age with the infants and children from group III.

\section{Methods}

\section{Polygraphic Recordings}

A polygraphic sleep recording of $2-4 \mathrm{hr}$ duration was obtained from each subject after a night feeding. Special care was taken to guarantee nearly identical conditions for each sleep recording. All infants and children were recorded in the same room in a crib or bed. Polygraphic recordings were done on an 8-channel Offner dynograph type $T$ and consisted of $(1)$ observed eye movements, registered by a push button; (2) respiration, registered by a thermistor attached to the infant's nose; (3) electromyogram of chin muscle activity; (4) facial and body activity, continuously observed during the recording and indicated by a code on the paper write-out; (5) EEG, recorded with silver/silver-chlorided stick-on electrodes in a montage of six bipolar 
leads from bilateral frontocentral, centro-occipital, and occipitotemporal regions. The electrode resistance was 6 kilo-ohms or less, pen deflection $5 \mathrm{~mm} / 50 \mu \mathrm{V}$, time constant $0.3 \mathrm{sec}$ and paper speed $1.5 \mathrm{~cm} / \mathrm{sec}$.

\section{Visual Analysis of Polygraphic Recordings}

All records were visually analyzed page-by-page (20sec epochs). The analyzer had no knowledge of the patients, i.e., age or status as PKU or control subject. Motor activity, eye movements, respiration, and EEG were described by the following coding systems.

Motor activity. The symbols were: 0 , eyes closed, no motor activity; 1 , eyes closed, facial muscle activity; 2 , eyes closed, limb muscle activity; 3 , eyes closed, total body activity; 4, eyes opening and closing; 5, eyes open, awake child.

Eye movements (with closed lids). The symbols were: 1 , no eye movements; 2 , rapid eye movements.

Respiration. The ratio of the shortest/longest breath-to-breath interval was calculated for each 20-sec epoch as an indicator of respiratory regularity.

Electroencephalogram. For evaluation of the EEG a coding system was used which assigns to each 20-sec epoch a number from 1 through 9 . This system was introduced by Parmelee $e t$ al. [53] as an extension of the Dement EEG sleep stages [16] and has been found particularly useful for younger age groups: 1 , low voltage, high frequency activity of the awake infant or child usually with eyes open; $2, \alpha$ or $\theta$ rhythm of the awake infant with eyes closed; 3 , mixed $\theta$ and $\delta$ activity of relatively low amplitude usually seen while falling asleep or during active sleep (Dement stage $I$ or REM); 4, regular $\theta$ activity with amplitude modulation (hypnagogic activity [35]), 5, mixed $\delta$ and $\theta$ activity of high amplitude but without sleep spindles; 6 , low amplitude $\theta$ and $\delta$ activity with sleep spindles (Dement stage II); 7, trace alternant activity of the newborn infant in quiet sleep; 8 , mixed $\delta$ and $\theta$ activity with sleep spindles (Dement stage III); 9, synchronous high amplitude $\delta$ activity (Dement stage $I V$ ). For visual analysis spindles were defined as a sequence of regular 12-16 cps waves of at least 0.4-sec duration.

The codes for all four variables were punched on IBM cards and the distribution of sleep states was calculated by the computer. The analysis was always done for complete and uninterrupted cycles, i.e., one quiet sleep and the following active sleep phase.

\section{EEG Computer Analysis}

In eight subjects who had untreated PKU (group I) and, correspondingly, in eight normal control children who were matched for age (group II), the EEG recordings have been investigated using the mathematic technique of spectral analysis. The mathematic principles and the application of spectral theory to EEG analysis have been discussed in detail by Walter $[63,64]$ and others $[11,18,19,36,39,65]$.

The function used in this study is the autospectrogram, or power spectrum, which has been mathematically defined by Walter [63]. The autospectrogram resolves an EEG recording into frequency components, assigning higher intensity values to those frequencies at which the bioelectric activity is most pronounced and most regular. The more subtle variations in the activity at higher frequencies are best seen by plotting the logarithm of intensity against frequency.

Artifact-free, 3-min samples of EEG were selected visually for each sleep state without knowledge of the patients. These data were digitized and the power spectra computed using a general program for "Time series spectrum estimation" [17].

\section{Method of Calculating Spindle Peak Power}

For those EEGs with prominent sigma rhythm or spindle activity, a peak appears in the autospectrogram in the 12-16 cps range (Fig. 7). The area under such a peak represents the bioelectric power, with units proportional to (microvolts) ${ }^{2}$ cycles per second. This area was calculated in the following manner. The intensity I was calculated for all frequencies from 0 to $25 \mathrm{cps}$ at 0.5 -cps intervals. This plot of intensity (or log intensity) versus frequency, i.e., the power spectrum, forms a curve with underlying shape suggesting a hyperbola, but with superimposed peaks (e.g., spindle peak) sometimes deviating from this hyperbola shape. The frequencies $f_{a}$ and $f_{b}$ at which the spindle peak begins and ends, i.e., leaves and returns to this assumed hyperbola, can be visually selected with a high reproducibility between selectors. Frequencies $f_{a}$ and $f_{b}$ were selected blindly, i.e., without knowing whether the subject was a patient with PKU or a control subject. The following areas were then calculated.

The area under the power spectrum curve between $f_{a}$ and $f_{b}$ is the sum of the areas of $n$ trapezoids, where $f_{0}=f_{a}, f_{1}, f_{2}, \ldots, f_{n}=f_{b}$ are the frequencies at 0.5-cps intervals between $f_{a}$ and $f_{b}$

$$
\sum_{p=1}^{n} 0.5\left[\frac{I\left(f_{p}\right)+I\left(f_{p}-1\right)}{2}\right]
$$

The area under a hyperbola connecting points $\left(\mathrm{f}_{\mathrm{a}}, \mathrm{I}\right.$ 
$\left.\left(\mathfrak{f}_{\mathfrak{a}}\right)\right)$ and $\left(\mathrm{f}_{\mathrm{b}}, \mathrm{I}\left(\mathrm{f}_{\mathrm{b}}\right)\right)$ is given by

$$
\int_{f_{z}}^{f_{b}}\left(\frac{\alpha}{f}+\beta\right) \text {. where } y=\frac{\alpha}{x}+\beta
$$

is the equation for a general hyperbola, and constants $\alpha$ and $\beta$ are calculated by the solution of the pair of equations

$$
\begin{gathered}
\left\{\begin{array}{l}
\mathrm{I}\left(\mathrm{f}_{\mathrm{a}}\right)=\frac{\alpha}{\mathrm{f}_{\mathrm{a}}}+\beta \\
\mathrm{I}\left(\mathrm{f}_{\mathrm{b}}\right)=\frac{\alpha}{\mathrm{f}_{b}}+\beta, \text { yielding }
\end{array}\right. \\
\alpha=\frac{\mathrm{f}_{\mathrm{a}} \mathrm{f}_{\mathrm{b}}\left[\mathrm{If} \mathrm{f}_{\mathrm{a}}-\mathrm{I}\left(\mathrm{f}_{\mathrm{b}}\right)\right]}{\mathrm{f}_{\mathrm{b}}-\mathrm{f}_{\mathrm{a}}} \text { and } \beta=\frac{\mathrm{f}_{b}[\mathrm{I}(\mathrm{fb})]-\mathrm{f}_{\mathrm{a}}\left[\mathrm{I}\left(\mathrm{f}_{\mathrm{a}}\right)\right]}{\mathrm{f}_{\mathrm{b}}-\mathrm{f}_{\mathrm{a}}}
\end{gathered}
$$

The difference between these areas is the power $\mathbf{P}$ of the spindle peak, i.e., the area enclosed by the power spectrum curve and the hyperbola $\alpha / f+\beta$ between $f_{a}$ and $\mathrm{f}_{\mathrm{b}}$

$$
P=\sum_{p=1}^{n} \frac{1}{4}\left[I\left(f_{p}\right)+I\left(f_{p}-1\right)\right]-\int_{f_{a}}^{f_{b}}\left(\frac{\alpha}{f}+\beta\right)
$$

\section{Definition of Sleep States}

The definition of sleep states is still controversial. Distribution of the two sleep states varies with the criteria used for active versus quiet, REM versus NREM, and paradoxical versus slow wave sleep. We consider futile any attempt to make every investigator agree on one definition. Therefore, we examined the distribution of sleep states as classified by several sets of criteria. One can split the record into many epochs of various behavioral states on the basis of minor differences, or one can lump similar epochs together on the basis of any one common variable. Using the three different ways of analyzing our records we hope to satisfy both the "splitters" and the "Iumpers."

REM versus NREM sleep. The distribution of REM and NREM sleep was determined solely by the presence or absence of rapid eye movements under closed lids for each 20-sec epoch of an uninterrupted sleep cycle.

Active sleep versus quiet sleep versus undifferentiated sleep. Active sleep was defined as follows: presence of rapid eye movements; presence of limb or body movements; irregular respiration with a ratio of the shortest/longest breath-to-breath interval of less than 0.9; EEG code 1, 2, or 3. Three of these four criteria had to be fulfilled in order to classify a single 20-sec epoch of an uninterrupted sleep cycle as active sleep.
Quiet sleep was defined as follows: absence of rapid eye movements; absence of any limb or body movements; regular respiration with a ratio of the shortest/ longest breath-to-breath interval of greater than 0.8 ; EEG code 4-9. Three of these four criteria had to be met in order to classify a single $20-\mathrm{sec}$ epoch of an uninterrupted sleep cycle as quiet sleep. All 20-sec epochs which could not thus be identified as either active or quiet sleep were classified as undifferentiated sleep.

Paradoxical versus slow wave sleep. The determination of paradoxical versus slow wave sleep distribution was based solely on the visual analysis of the paper write-out record. The first occurrence of sleep spindles after the disappearance of rapid eye movements was defined as the beginning of phase 1,3 , or 5 , respectively (subsequent slow wave sleep phases were thus given odd numbers). The first occurrence of rapid eye movements together with a change in the EEG from $\delta$ to $\theta / \delta$ activity with lower amplitude and without sleep spindles was defined as phase 2,4 , or 6 , respectively (subsequent paradoxical sleep phases were thus given even numbers). For this procedure the interpreter was allowed $3 \mathrm{~min}$ to decide when to define the change from one phase to the other, in order to allow him to rely also on the other recorded parameters and to neglect single eye movements or single sleep spindles.

Quiet sleep stages. After the 46th week of conceptional age (i.e., 6 weeks after term birth), quiet sleep periods last longer than in the neonatal period and the EEG patterns begin to differentiate according to the Dement sleep stages $I I, I I I$, and $I V$ [16]: stage II, relatively low amplitude theta activity with sleep spindles; to $\theta / \delta$ activity with lower amplitude and without stage III, mixed $\theta / \delta$ activity of high amplitude with sleep spindles; stage $I V$, high amplitude $\delta / \theta$ activity usually without sleep spindles.

Although all four of the Dement stages are well expressed only toward the end of the 1st year, both visual and computer analysis of the EEG disclose some of the characteristic changes of the EEG during quiet sleep as early as 3 months after term birth. Therefore, after 44 weeks of conceptional age, each quiet sleep state was divided into three consecutive periods of equal length, called quiet sleep $I I, I I I$, and $I V$. These digits were chosen with references to the Dement quiet sleep stages although, obviously, our quiet sleep periods do not always coincide with the Dement stages. An infant 3 months after term birth, for example, does not have any well expressed EEG pattern of Dement stage IV. 


\section{Results}

No significant differences in the distribution of quiet, active, and undifferentiated sleep could be detected between infants with untreated PKU and either the treated or control infants (Fig. 1). In fact, the percentages of $20-\mathrm{sec}$ epochs with the different sleep states

\begin{tabular}{|c|c|c||c|c|}
\hline & $\begin{array}{c}\text { PKU } \\
\text { untreated } \\
N=22\end{array}$ & $\begin{array}{l}\text { control infants } \\
N=22\end{array}$ & $\begin{array}{c}\text { PKU } \\
\text { untreoted } \\
N=13\end{array}$ & $\begin{array}{c}\text { PKU } \\
\text { treated } \\
N=13\end{array}$ \\
\hline QUIET SLEEP & $\begin{array}{r}61,2 \pm 20,0 \\
n=29\end{array}$ & $\begin{array}{r}60,7 \pm 21,5 \\
n=29\end{array}$ & $\begin{array}{r}68,0 \pm 17,8 \\
n=17\end{array}$ & $\begin{array}{r}65,4 \pm 16,7 \\
n=17\end{array}$ \\
\hline UNDIFF. SLEEP & $\begin{array}{r}8,1 \pm 4,5 \\
n=29\end{array}$ & $\begin{array}{r}6,9 \pm 4,2 \\
n=29\end{array}$ & $\begin{array}{r}6,7 \pm 3,8 \\
n=17\end{array}$ & $\begin{array}{r}7,4 \pm 3,9 \\
n=17\end{array}$ \\
\hline ACTIVE SLEEP & $\begin{array}{r}30,6 \pm 19,1 \\
n=29\end{array}$ & $\begin{array}{r}32,4 \pm 20,7 \\
n=29\end{array}$ & $\begin{array}{r}25,4 \pm 16,1 \\
n=17\end{array}$ & $\begin{array}{r}27,2 \pm 15,3 \\
n=17\end{array}$ \\
\hline
\end{tabular}

$N=$ no. of infants

$n=n o$. of cycles analysed

Fig. 1. Sleep cycles in phenylketonuria $(P K U)$. Quiet sleep versus undifferentiated (UNDIFF.) sleep versus active sleep. Numbers represent mean \pm 1 so of percentage of 20 -sec epochs in each sleep state.

\begin{tabular}{|c|c|c|c|c|}
\hline & $\begin{array}{c}\text { PKU } \\
\text { untreated } \\
N=22\end{array}$ & $\begin{array}{l}\text { control infants } \\
\mathrm{N}=22\end{array}$ & $\begin{array}{c}P K U \\
\text { untreated } \\
N=13\end{array}$ & $\begin{array}{c}\text { PKU } \\
\text { treated } \\
N=13\end{array}$ \\
\hline N REM SLEEP & $\begin{aligned} & 65,5 \pm 21,0 \\
& n=29\end{aligned}$ & $\begin{array}{r}65,4 \pm 18,2 \\
n=29\end{array}$ & $\begin{aligned} & 70,1 \pm 22,7 \\
& n=17\end{aligned}$ & $\begin{array}{r}69,7 \pm 18,0 \\
n=17\end{array}$ \\
\hline QUIET SLEEP & $\begin{array}{r}61,2 \pm 20,0 \\
n=29\end{array}$ & $\begin{array}{r}60,7 \pm 21,5 \\
n=29\end{array}$ & $\begin{array}{r}68,0 \pm 17,8 \\
n=17\end{array}$ & $\begin{array}{r}65,4 \pm 16,7 \\
n=17\end{array}$ \\
\hline SLOW-WAVE-SLEEP & $\begin{array}{r}59,6 \pm 19,8 \\
n=29\end{array}$ & $\begin{array}{r}57,4 \pm 18,5 \\
n=29\end{array}$ & $\begin{array}{r}63,5 \pm 16,7 \\
n=17\end{array}$ & $\begin{aligned} 62,0 \pm 17,7 \\
n=17\end{aligned}$ \\
\hline
\end{tabular}

Fig. 2. Sleep cycles in phenylketonuria $(P K U)$. Comparison of percentage of 20 -sec epochs satisfying the three sets of criteria for non-rapid eye movement $(N R E M)$ sleep, quiet sleep, and slow wave sleep.

\begin{tabular}{|c|r|r||c|r|}
\hline SLOW-WAVE-SLEEP & $\begin{array}{c}\text { PKU } \\
\text { untreated } \\
N=22\end{array}$ & $\begin{array}{c}\text { control infants } \\
N=22\end{array}$ & $\begin{array}{c}\text { PKU } \\
\text { untreated } \\
N=13\end{array}$ & $\begin{array}{c}\text { PKU } \\
\text { treated } \\
N=13\end{array}$ \\
\hline I. CYCLE & $\begin{array}{r}57,0 \pm 20,5 \\
n=21\end{array}$ & $\begin{array}{r}58,2 \pm 19,7 \\
n=21\end{array}$ & $\begin{array}{r}60,4 \pm 18,2 \\
n=12\end{array}$ & $\begin{array}{r}64,9 \pm 17,2 \\
n=12\end{array}$ \\
\hline II. CYCLE & $\begin{array}{r}66,2 \pm 17,2 \\
n=8\end{array}$ & $\begin{array}{r}55,6 \pm 16,2 \\
n=8\end{array}$ & $\begin{array}{r}71,1 \pm 9,9 \\
n=5\end{array}$ & $\begin{array}{r}55,0 \pm 18,3 \\
n=5\end{array}$ \\
\hline I. \&II. CYCLE & $\begin{array}{r}59,6 \pm 19,8 \\
n=29\end{array}$ & $\begin{array}{r}57,4 \pm 18,5 \\
n=29\end{array}$ & $\begin{array}{r}63,5 \pm 16,7 \\
n=17\end{array}$ & $\begin{array}{r}62,0 \pm 17,7 \\
n=17\end{array}$ \\
\hline
\end{tabular}

$N=n o$. of infants $\quad n=n o$. of cycles analysed

Fig. 3. Sleep cycles in phenylketonuria $(P K U)$. Percentage of 20 -sec epochs with slow wave sleep in first cycle $(I)$, second cycle $(I I)$, and sum of first two cycles $(I$ o $I I)$. were strikingly similar. The result was independent of the criteria for the definition of sleep states. Whether relying only on eye movements (NREM versus REM sleep), considering both EEG and eye movements (slow wave versus paradoxical sleep), or using three out of four criteria for the definition of quiet versus active sleep, we were not able to detect differences in the distribution of sleep states between control subjects and those with PKU, or between treated and untreated phenylketonuric children (Fig. 2). Comparing the distributions based on the three sets of criteria for determining sleep states, the same recordings always contained more NREM sleep than quiet sleep and, in turn, more quiet sleep than slow wave sleep. This result is not surprising. Our criteria for quiet sleep have more conditions than just absence of eye movements. On the other hand, quiet sleep criteria include more than just slow wave EEG activity, since a few epochs with fast wave activity met the other three out of four criteria for quiet sleep and were, therefore, included in quiet sleep. When the 1st and 2nd sleep cycles were analyzed separately, small and insignificant differences between control subjects and phenylketonuric children could be detected (Fig. 3). However, the differences in one cycle were always such that they were almost exactly counteracted by the distribution of sleep states in the next cycle.

Children with PKU had significantly more sleep

\begin{tabular}{|c|c|c|c|c|}
\hline & $\begin{array}{c}\text { PKU } \\
\text { untreated }\end{array}$ & control infants & $\begin{array}{c}\text { PKU } \\
\text { untreated }\end{array}$ & $\begin{array}{l}\text { PKU } \\
\text { treated }\end{array}$ \\
\hline \multirow{2}{*}{ PHASE 1} & $48,4 \pm 30,1^{*}$ & ${ }^{*} 32,9 \pm 33,3$ & $64,1 \pm 24,6$ & $72,2 \pm 27,1$ \\
\hline & $N=21 \quad n=21$ & $N=21 \quad n=21$ & $N=12 \quad n=12$ & $N=12 \quad n=12$ \\
\hline \multirow{2}{*}{ PHASE 3} & $58,8 \pm 32,2^{* *}$ & ${ }^{* *} 40,8 \pm 31,9$ & $79,2 \pm 14,5$ & $72,0 \pm 26,4$ \\
\hline & $N=18 \quad n=18$ & $N=18 \quad n=18$ & $N=12 \quad n=12$ & $N=12 \quad n=12$ \\
\hline \multirow{2}{*}{ PHASE 5} & $70,6 \pm 32,1^{* *}$ & ${ }^{* *} 31,2 \pm 34,2$ & $75,7 \pm 13,5$ & $77,2 \pm 25,4$ \\
\hline & $N=6$ & $N=6 \quad n=6$ & $n=3$ & $N=3$ \\
\hline \multirow{2}{*}{ ALl ood PHASES } & $55,5 \pm 31,5^{* * *}$ & $3 * * * 0+32,4$ & $72,1 \pm 20,3$ & $72,7 \pm 25,6$ \\
\hline & $N=22 \quad n=45$ & $N=22 \quad n=45$ & $N=13 \quad n=27$ & $N=13 \quad n=27$ \\
\hline AGE RANGE & $16 d-3^{9} / 12$ yrs. & $20 \mathrm{~d}-4^{3} / 12 \mathrm{yrs}$. & $43 d .-3^{9 / 12 y r s .}$ & $45 \mathrm{~d} .-3^{10} / 12 \mathrm{yrs}$. \\
\hline AVERAGE AGE & $361 d$. & $364 \mathrm{~d}$. & $483 \mathrm{~d}$ & $461 \mathrm{~d}$. \\
\hline $\begin{array}{l}\text { Significance lev } \\
N=\text { no. of infont }\end{array}$ & (WILCOXON & $* 0,025$ & $* * *$ & \\
\hline
\end{tabular}

Fig. 4. Sleep spindles in slow wave sleep. Percentage of 20-sec epochs with spindle activity in sequential phases of slow wave sleep, by visual analysis. The difference between untreated patients with phenylketonuria $(P K U)$ (column 2) and control infants (column 3) is statistically significant. There is no difference between untreated (column 4) and treated (column 5) infants with PKU. The apparent difference between the untreated infants with PKU of column 2 and column 4 is due to the difference in average age. 
spindles within all slow wave sleep phases (Fig. 4), in confirmation of preliminary results obtained in our laboratory [25]. Poley and Dumermuth [55] observed a greater amount of high frequency activity in children with PKU. Dietary treatment with a successful reduction of phenylalanine blood levels did not immediately reduce the number of sleep spindles compared with phenylketonuric children without treatment.

The EEG power spectra support these findings of visual analysis with regard to sleep spindle development. At 5 weeks from birth (45 weeks conceptional age) a power peak between $12-16 \mathrm{cps}$ is visible only in infants with PKU (Fig. 5). At this age sleep spindles do not yet occur in normal infants [41, 49, 58]. In a 10week-old with infant PKU the 12--16-cps peak is even

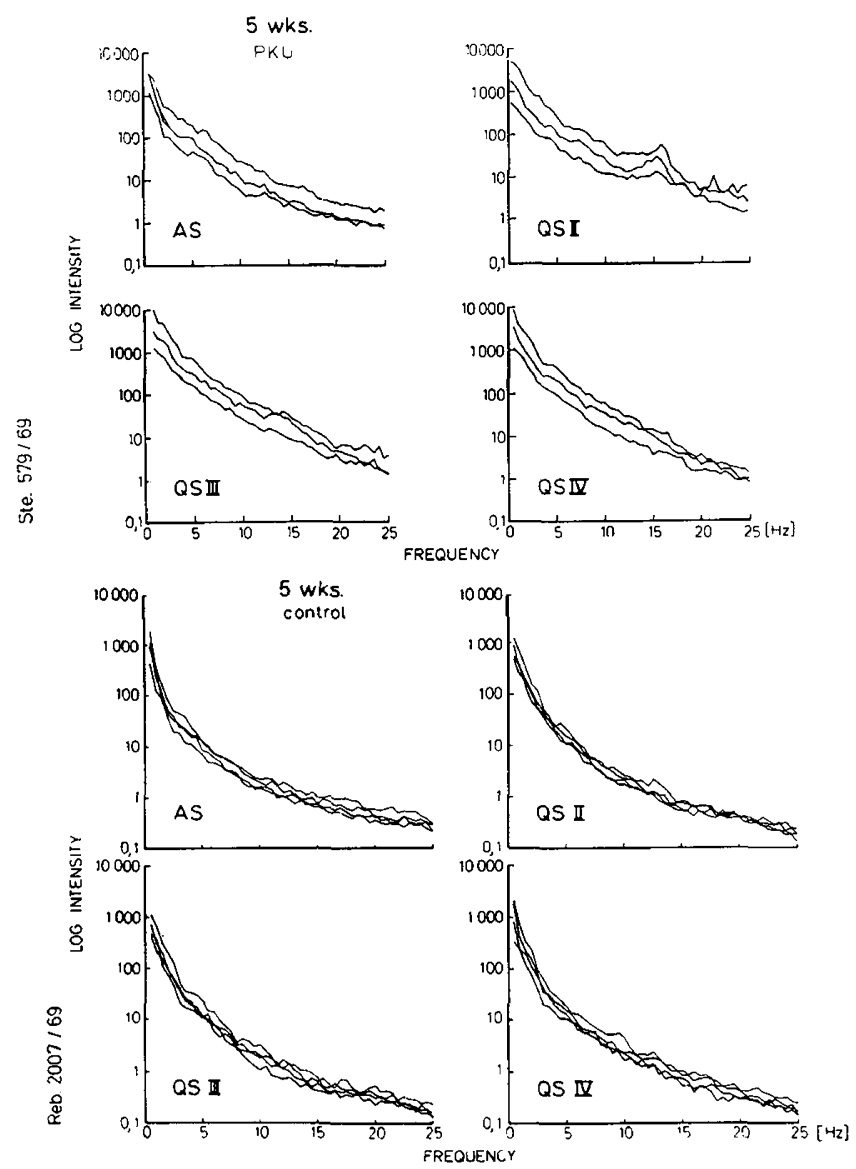

Fig. 5. Autospectrograms of infant with phenylketonuria $(P K U)$ (upper) and normal (lower) infant at 5 weeks after term birth. Abscissa: Frequency in Hertz (cycles per second). Ordinate: Intensity (logarithmic scale), units proportional to (microvolts) ${ }^{2}$. The four (or three) lines of each spectrogram represent various electroencephalographic leads: $\mathrm{FP}_{2}-\mathrm{C}_{4}, \mathrm{FP}_{1}-\mathrm{C}_{3}, \mathrm{C}_{4}-\mathrm{O}_{2}, \mathrm{C}_{3}-\mathrm{O}_{1}$. AS: Active sleep; $Q S$ : quiet sleep. Infant with $\mathrm{PKU}$ has spindle peak around $15 \mathrm{cps}$ in second stage of quiet sleep ( $Q S I I)$. Control infant has no spindle peak.
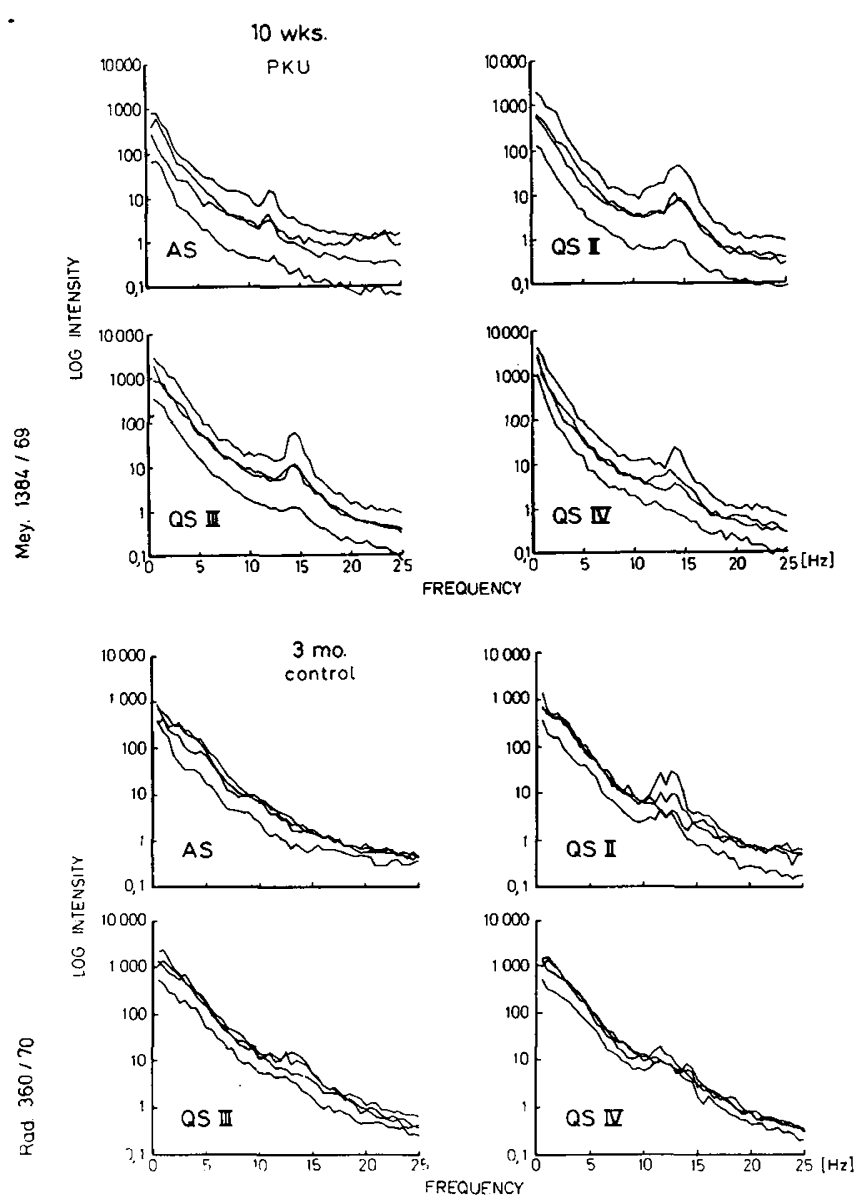

Fig. 6. Autospectrograms of infant with phenylketonuria $(P K U)$ at 10 weeks (upper) and control infant at 12 weeks (lower) after term birth. Infant with PKU has prominent spindle peaks in all states and stages of sleep. Control infant has peak in QS II only. $Q S$ : Quiet sleep; $A S$ : active sleep.

higher than in a 12-week-old normal baby. Furthermore, at this age the sleep spindles in PKU may occur in all sleep stages, sometimes even in active sleep, whereas normal children at this age usually have spindle activity only in quiet sleep stage II (Fig. 6). In PKU the spindle power peak is frequently abnormally shaped with two, or even three separate peaks (Fig. 7). Our findings on spindle peak power in eight PKU subjects compared with eight normal children matched for age are summarized in Figure 8. The area under the spindle peak, i.e., the bioelectric power in the 12- -16-cps range is greater in children with PKU than in normal children. Moreover, the frequency within the sleep spindles is higher in children with PKU (Fig. 9).

Subjects with PKU have fewer monomorphic $\theta$ waves, i.e., hypnagogic theta activity [35], compared 

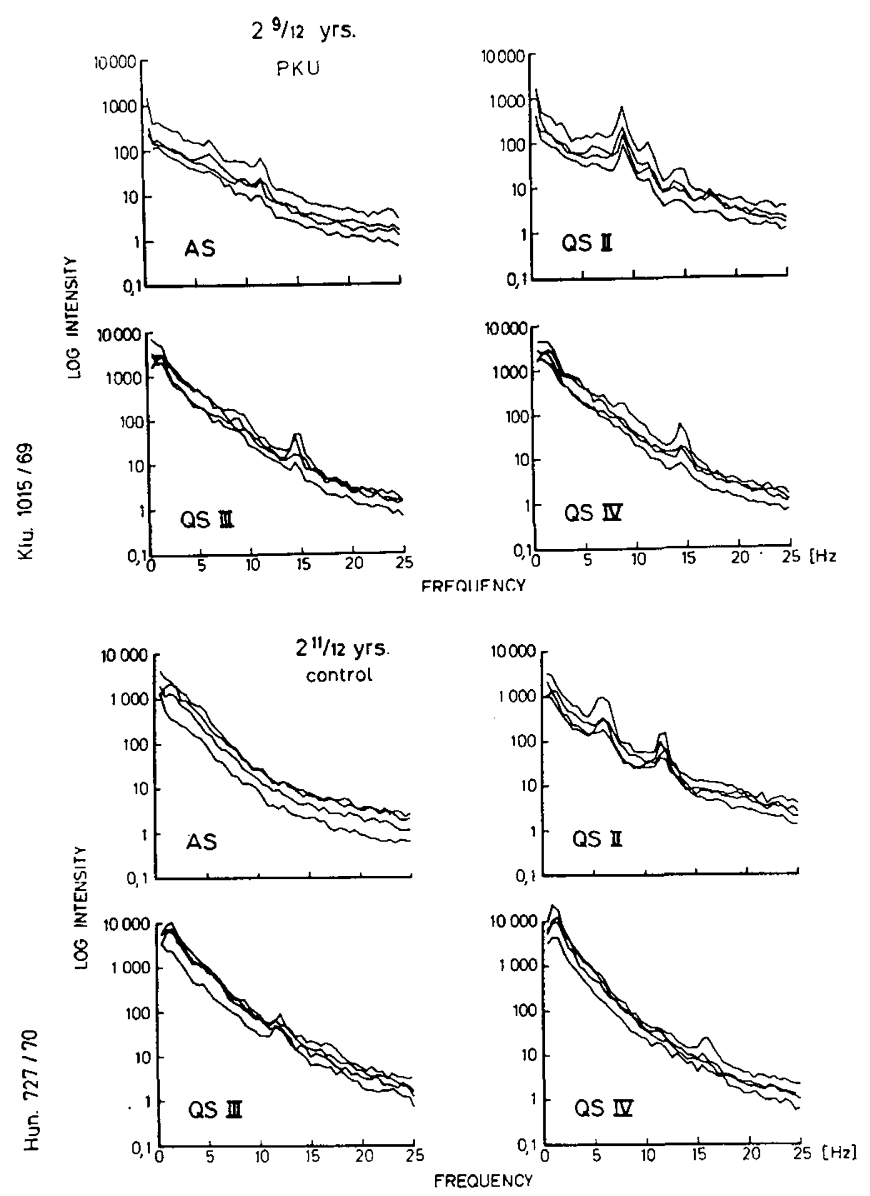

Fig. 7. Autospectrograms of subject with phenylketonuria $(P K U)$ at 2 years 9 months (upper) and control (lower) at 2 years 11 months. Child with PKU still has spindle peaks in all stages. Note multiple peaks in QS (quiet sleep) II, including prominent peak at $9 \mathrm{cps}$. Control child has smaller spindle peaks, still greatest in QS II. Peak at 5 cps in QS II represents normal monomorphic hypnagogic theta activity.

with control children (Fig. 10). The markedly diminished amount of hypnagogic activity in the subjects with PKU did not increase after short term dietary treatment despite normal blood phenylalanine levels. This finding, however, requires some further analysis. Of the six EEGs of normal children 1 year or older for whom power spectra were computed, four out of five older than 1.5 years had hypnagogic power peaks between 4 and $6 \mathrm{cps}$. The fifth had no peak below $11 \mathrm{cps}$. The other EEG, of a 1-year-old normal child, had a small peak at $10 \mathrm{cps}$ [58]. Of 10 EEGs of children with PKU who were older than 1 year for whom power specira were computed, eight had a prespindle power peak. However, this peak was always at higher frequencies than the hypnagogic or drowsy waves in nor-

\begin{tabular}{|c|c|c|}
\hline & $\begin{array}{l}\text { MEAN POWER } \\
\text { of Spindle Peaks } \\
( \pm 1 \text { s.d.) }\end{array}$ & $\begin{array}{l}\text { MEAN POWER } \\
\text { including Zero Value } \\
\text { where Peak is Absent }\end{array}$ \\
\hline NORMAL & $30.2 \pm 37.5$ & 12.6 \\
\hline$N=8$ & $n=24$ & $n=64$ \\
\hline PKU & $37.4 \pm 383$ & 18.7 \\
\hline$N=8$ & $n=32$ & $n=64$ \\
\hline
\end{tabular}

$N=$ number of EEG recordings analysed

$n=$ number of spindle peaks in all sleep states, both hemispheres

Fig. 8. Spindle peak power from power spectra of leads $\mathrm{FP}_{2}-\mathrm{C}_{4}$ and $\mathrm{FP}_{1}-\mathrm{C}_{3}$, i.e., integrated area under peak; units proportional to (microvolts) ${ }^{2} \cdot$ cycles per second. First column: Mean power of all spindle peaks present. Normal subjects had 24 of a possible maximum 64 peaks. Subjects with phenylketonuria had 32 of possible 64. Second column: Mean power with $n=64$ as divisor. $E E G$ : Electroencephalogram.

\begin{tabular}{|c|c|c|}
\cline { 2 - 3 } \multicolumn{1}{c|}{} & $\begin{array}{c}\text { MAXIMUM } \\
\text { (mean } \pm 1 \text { s.d. })\end{array}$ & $\begin{array}{c}\text { RANGE } \\
\text { (mean of onset and end) }\end{array}$ \\
\hline NORMAL & $x_{12.8 \pm 1.3}$ & $11.4-14.9$ \\
N=8 & $n=24$ & $\pm 1.4 \quad \pm 1.4$ \\
\hline PKU & $x_{14.1} \pm 1.4$ & $12.4-16.3$ \\
N=8 & $n=32$ & $\pm 1.7 \quad \pm 1.6$ \\
\hline
\end{tabular}

* significant difference $\alpha=0.001$ (Wilcoxon-Mann-Whitney test) $\mathrm{N}=$ number of EEG recordings analysed

$n=$ number of spindle peaks in all sleep states, both hemispheres

Fig. 9. Mean frequency (cycles per second) of electrical activity within spindle bursts from power spectra leads $\mathrm{FP}_{2}-\mathrm{C}_{4}$ and $\mathrm{FP}_{1}-\mathrm{C}_{3}$. Maximum: Frequency of highest point of peak on autospectrogram; Range: mean onset and end of peaks $\left(f_{a}\right.$ and $f_{b}$ in text). EEG: Electroencephalogram.

\begin{tabular}{|c|r|r||r|r|}
\hline & $\begin{array}{c}\text { PKU } \\
\text { untreated } \\
N=22\end{array}$ & $\begin{array}{c}\text { Control infants } \\
N=22\end{array}$ & $\begin{array}{c}\text { PKU } \\
\text { untreated } \\
N=13\end{array}$ & $\begin{array}{c}\text { PKU } \\
\text { treated } \\
N=13\end{array}$ \\
\hline SLOW-WAVE-SLEEP & $\begin{array}{r}0,76 \pm 3,01 \\
n=45\end{array}$ & $\begin{array}{r}0,66 \pm 6,83 \\
n=45\end{array}$ & $\begin{array}{r}0,96 \pm 3,58 \\
n=27\end{array}$ & $\begin{array}{r}0,88 \pm 3,85 \\
n=27\end{array}$ \\
\hline FAST -WAVE-SLEEP & $\begin{array}{r}0,44 \pm 2,16 \\
n=30\end{array}$ & $\begin{array}{r}* * 25 \pm 12,0 \\
n=30\end{array}$ & $\begin{array}{r}0,0 \pm 0,0 \\
n=18\end{array}$ & $\begin{array}{r}0,17 \pm 0,52 \\
n=18\end{array}$ \\
\hline ALL SLEEP & $\begin{array}{r}0,63 \pm 2,69 \\
n=75\end{array}$ & $\begin{array}{r}{ }^{* *}, 89 \pm 8,07 \\
n=75\end{array}$ & $\begin{array}{r}0,57 \pm 2,79 \\
n=45\end{array}$ & $\begin{array}{r}0,60 \pm 2,99 \\
n=45\end{array}$ \\
\hline
\end{tabular}

Significance level (WILCOXON test) $* * 0,01 \quad * * * 0,005$ $N=$ no. of infants $\quad n=$ no. of phases analysed

Fig. 10. Hypnagogic activity. Percentage of 20-sec epochs with monomorphic 4-6 cps waves. $P K U$ : Phenylketonuria. 
mal children over 1 year of age (Fig. 11). Thus, either hypnagogic activity does not occur in subjects with PKU, or its frequency is shifted to higher values. From their shape as well as their occurrence during the initiation of sleep and between periods of active and quiet sleep, we assume that the 7--11-cps rhythmic activity

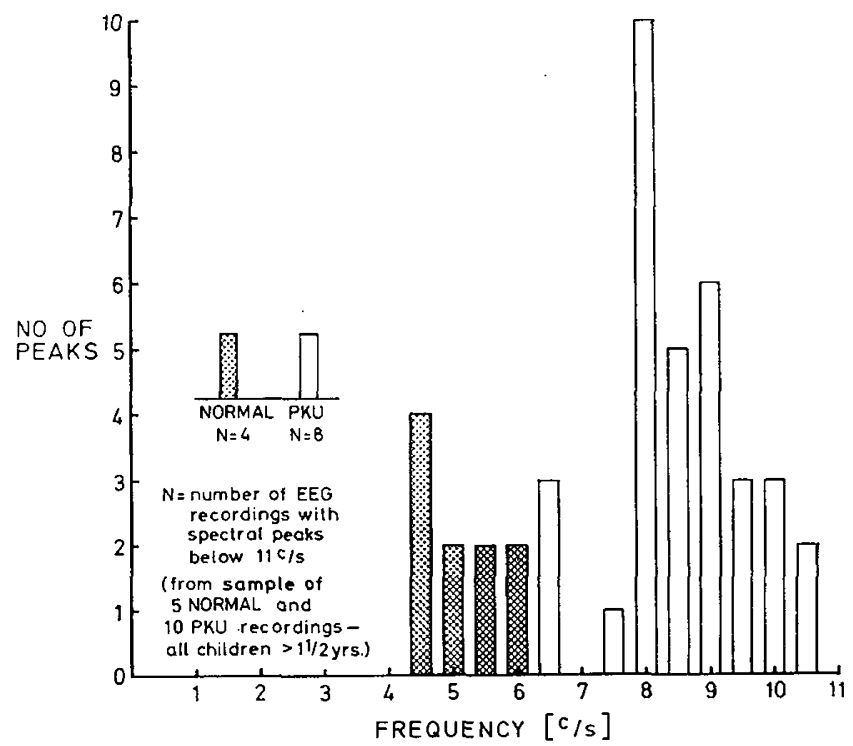

Fig. 11. Hypnagogic and/or prespindle peaks from power spectra of leads $\mathrm{FP}_{2}-\mathrm{C}_{4}$ and $\mathrm{FP}_{1}-\mathrm{C}_{3}$. Histogram of all power spectral peaks below $11 \mathrm{cps}$ in children older than 1.5 years. Of normal recordings, 4 out of 5 had such peaks (below $11 \mathrm{cps}$ ) and of phenylketonuria $(P K U)$ recordings, 8 out of 10 had them. All peaks (10) from these four normal electroencephalograms ( $E E G s$ ) were between 4 and 6 cps, whereas all peaks [33] from the 8 PKU EEGs were between 7 and $11 \mathrm{cps}$. in PKU does represent an abnormally high frequency version of hypnagogic activity (Fig. 12).

\section{Discussion}

\section{Relevance of Results in Relation to Biochemical Theories of Sleep}

Our results do not support the hypothesis that serotonin regulates the distribution of active versus quiet sleep. The discrepancy between the results obtained by Petre-Quadens and Jouvet [54] and by Feinberg et al. [20] and our results may be because these authors mainly investigated adult subjects. Long lasting mental retardation with convulsions and myelination deficits $[1,13,22,45,56]$ rather than a disturbance in the noradrenaline/serotonin balance may account for the decreased amount of REM sleep found by these authors in many different mental retardates including subjects with PKU. Petre-Quadens and Jouvet [54] did all night recordings and Feinberg et al. [20] even studied several consecutive nights, whereas our results are based on the analysis of a few total sleep cycles. After a pilot study with all night recordings in three children with PKU and three normal children showed no difference in the distribution of quiet versus active sleep, we did not pursue this further.

In PKU the synthesis of epinephrine is also affected [66]. Nadler and Hsia [50] were able to demonstrate a decrease of norepinephrine and epinephrine in the plasma and of dopamine, norepinephrine, and epinephrine in the urine of phenylketonuric children. In

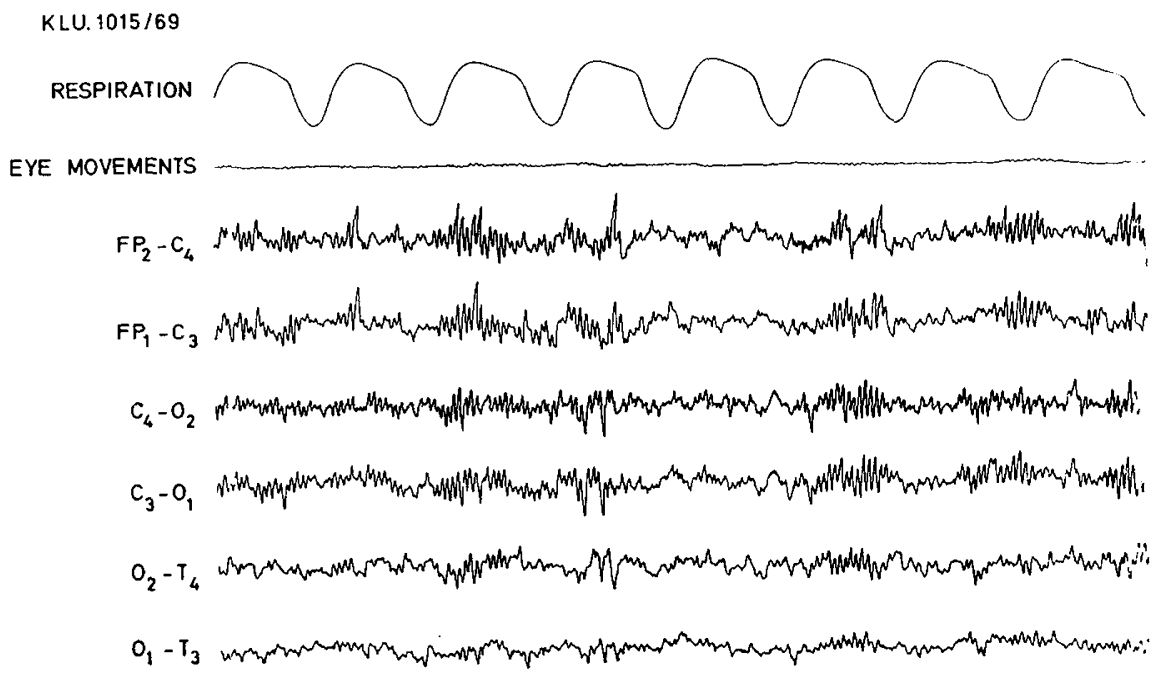

Fig. 12. Polygraphic record of 2.75-year-old phenylketonuric ( $P K U)$ subject (from Fig. 7) showing abnormal 7-11 cps activity. 
all instances this decrease was reversible when PKU was treated with a low phenylalanine diet. Although the changes of these biogenic amine concentrations were rather small, they contaminate our results and weaken their relevance for the biochemical theories of sleep. However, experimental studies with intravascular, intracerebral, or intraventricular administration of serotonin, $p$-chlorophenylalanine, 5-hydroxytryptophan, or monoamine oxidase inhibitors do not provide a more convincing experimental approach, because these drugs are also acting upon both serotonin and catecholamines [33].

The failure to show any abnormality in the distribution between quiet and active sleep in infants and children with PKU may be because, quite contrary to experimental situations in animals, the blood and cerebrospinal fluid serotonin level is chronically reduced and not abruptly decreased. Even the normalization of serotonin levels after the initiation of a low phenylalanine diet takes about 4 weeks [52]. Therefore, it is not surprising that we did not find any change in sleep state distribution or in the amount of sleep spindle activity within 6 weeks after the initiation of dietary treatment. Last, but not least, our results could indicate that serotonin has nothing to do with the normal regulation of sleep states. At least we must assume that under chronic conditions a normal or near normal sequence of quiet and active sleep can be maintained despite a severe lack of serotonin.

Monoamine oxidase inhibitors (nialamide), which increase the amount of brain serotonin, produce long lasting slow wave sleep with excessive spindling in the EEG of cats [31]. In contrast, we found excessive spindling in infants with PKU who have little blood and cerebrospinal fluid serotonin. Furthermore, the bioelectric activity within PKU spindles has a higher than normal frequency. This finding can be explained on the basis of the apparent importance of serotonin in regulating inhibitory synaptic processes in the brain stem, the limbic lobe, and the hypothalamus [51]. If, as proposed by Andersen and Andersson [2], sleep spindles are originated in the thalamus by means of balanced activity between excitatory and recurrent inhibitory neurons, a lack of inhibitory transmitter could account for an increased amount of sleep spindles with higher than normal frequency. A model for this effect was proposed by Andersen and Eccles [3]. They have hypothesized that the thalamic recurrent inhibitory mechanism is responsible for the pauses between spindle bursts as well as for the spindles themselves, the former through recurrent postsynaptic inhibition and the latter through "post-inhibitory rebound." Thus, inhibitory interneurons in the thalamus determine the onset, duration, and frequency of spindle discharges. They further postulate that after the post-inhibitory period, many participating neurons are in a state of hyperexcitability, which accounts for the rhythmicity of the spindle activity. It is interesting to note that the other regular rhythmic phenomenon in the sleep EEG, the hypnagogic $\theta$ activity (4-6 cps), is also shifted toward higher frequencies (7-11 cps) in children with PKU. Perhaps neuronal mechanisms similar to those responsible for the thalamic origin of sleep spindles account for the generation of hypnagogic activity as well.

Sleep Spindles, Brain Development, and Effect of Dietary Treatment of $P K U$

The rhythmic sleep spindle activity seems to be a very sensitive indicator of abnormal brain development. In the infants with PKU, abnormal spindle activity could already be seen 5 weeks after term birth, the EEG abnormalities increasing with age and severity of the mental defect. The increased amount of sleep spindles with longer duration and shorter spindle to spindle intervals was substantiated by visual analysis of the paper write-out. This result was confirmed by automatic spectral analysis, although with this method, not only sleep spindles, but also continuous 11- -15-cps activity, accounted for the 11- -15-cps activity peak.

Because the age of onset, the developmental course during the 1st year of life, the amount and the frequency of sleep spindles are very consistent in normal infants; it seems that normal brain development is not compatible with deviant generation of sleep spindles. In contrast to PKU, in hypothyroidism we have found the development of sleep spindles to be severely retarded or absent [42, 59]. Furthermore, Gibbs and Gibbs [23] found "extreme spindles" in children with mental retardation.

No significant change in the amount and the frequency of sleep spindles was seen within 4-6 weeks after the initiation of dietary treatment. This could be because about 4 weeks are apparently required for the normalization of tryptophan metabolism and the restitution of blood serotonin [52].

It is unlikely that the abnormal tryptophan metabolism with lack of serotonin is responsible for the mental defect in PKU. There is widespread agreement that 
normal intellectual development can only be achieved when therapy begins very early and is strictly maintained during childhood $[7,8,21,27,30,34]$, although normalization of serotonin levels can be achieved by the initiation of treatment at any age. However, certain therapeutic improvements of motor behavior have been reported, even when therapy was started late in infancy or during childhood, e.g., increased ability of locomotion, decrease of muscle tone and excitability, increased awareness of the surroundings, disappearance of seizure activity both clinically and in the EEG $[4,9,12,26,43,44,67]$. It is not known why such differences exist between the intellectual development on one hand and motor behavior and seizure activity on the other [48]. The changes in motor behavior and in the EEG may be due at least in part to the correction of tryptophan metabolism with an increase in serotonin as a brain stem inhibitory transmitter.

A detailed comparative study of intellectual functions, motor behavior, and sleep spindle development, along with the well known biochemical changes under low phenylalanine diet in PKU, has been initiated in our laboratory. The ultimate goal is not to discover one cause of all developmental anomalies in PKU, but to establish relations between several of them.

\section{Summary}

The distribution of sleep states and the sleep EEG were analyzed in infants and children with phenylketonuria before and after dietary treatment.

The percentage of time spent in active, quiet, and undifferentiated sleep was almost identical in untreated and treated phenylketonuric children as well as in control children matched for age. Our results do not support the hypothesis that serotonin regulates the distribution of active versus quiet sleep; in chronic conditions a normal or near normal sequence of quiet and active sleep can be maintained despite a severe lack of serotonin.

The number of sleep spindles and the bioelectric power in the 12--16-cps range were higher in infants and children with phenylketonuria compared with controls. No difference in sleep spindle activity could be detected between children with untreated phenylketonuria and those with 4-6 weeks of dietary treatment. Compared with normal infants, the frequency of the waves within sleep spindles was higher in patients with PKU, and the shape of the spindle peaks in the EEG power spectra was frequently abnormal.
There is strikingly little monomorphic $\theta$ activity in children with PKU. The hypnagogic or drowsy activity has been shifted to higher frequencies in the range of 7-11 cps.

The increased amount of high frequency spindle and drowsy activity in PKU can be explained by a decrease in blood and brain serotonin and $\gamma$-aminobutyric acid as inhibitory transmitters on the basis of the Andersen and Andersson hypothesis on the generation of rhythmic thalamocortical activity.

\section{References and Notes}

1. Alvord, E. C., Stevenson, L. D., Vogel, F. S., And Engle, R. L.: Neuropathological findings in phenyl-pyruvic oligophrenia (phenyl-ketonuria). J. Neuropath. Exp. Neurol., 9: 298 (1950).

2. Andersen, P., And Andersson, S. A.: Physiological basis of the alpha rhythm. (Appleton-Century-Crofts, New York, 1968).

3. Andersen, P., AND Ecckes, J. C.: Inhibitory phasing of neuronal discharge. Nature, 196: 645 (1962).

4. Armstrong, M. D., and Tyler, F. H.: Studies on phenylketonuria. I. Restricted phenylalanine intake in phenylketonuria. J. Clin. Invest., 34: 565 (1955).

5. Barbato, L. M., and Barbato, I. M.: In vitro inhibition of brain metabolism during postnatal development by high levels of phenylalanine and tryptophan. Brain Res., 13: 569 (1969).

6. Berendes, H., Anderson, J. A., Ziegler, N. R., and RuttenBERG, D.: Disturbance in tryptophan metabolism in PKU. Amer. J. Dis. Child., 96: 430 (1958).

7. Berman, P. W., Waisman, H. A., and Graham, F. K.: Intelligence in treated phenylketonuric children: a developmental study. Child Develop., 37: 731 (1966).

8. BICKEL, H.: Recent advances in the early detection and treatment of inborn errors with brain damage. Neuropädiatrie, $1: 1$ (1969).

9. Blainey, J. D., ANd Gulliford, R.: Phenylalanine-restricted diets in the treatment of phenylketonuria. Arch. Dis. Childhood, 31: 452 (1956).

10. BRADLEY, P. B.: The effects of 5-hydroxytryptamine on the electrical activity of the brain and on behaviour in the conscious cat. In: G. P. Lewis: 5-Hydroxytryptamine, p. 214. (Pergamon, London, 1958).

11. Canlle, E. J.: Apport de l'analyse spectrale de l'EeG dans l'étude des relations entre sommeil lent et sommeil onirique. Soc. Psychol. Franç., May 7 (1967).

12. Centerwall, W. R., Centerwall, S. A., Armon, V., and ManN, L. B.: Phenylketonuria. II. Results of treatment of infants and young children. J. Pediat., 59: 102 (1961).

13. Crome, L., Tymms, V., ANd Woolf, L. I.: A chemical investigation of the defects of myelination in phenylketonuria. $J$. Neurol. Neurosurg. Psychiat., 25: 143 (1962).

14. Davison, A. N., AND SANDLER, M.: Inhibition of 5-hydroxytryptophan decarboxylase by phenylalanine metabolites. Nature, 181: 186 (1958).

15. Delorme, F., Fromment, J. L., And Jouvet, M.: Suppression du sommeil par la $p$. chlorométhamphétamine et la $p$. chlorophénylalanine. C. R. Soc. Biol. (Paris), 160: 2347 (1966). 
16. Dement, W., and Klemtman, N.: Cyclic variations in EEG during sleep and their relation to eye movements, body motility and dreaming. Electroencephalogx. Clin. Neurophysiol., 9: 673 (1957).

17. Dixon, W. J.: BMDX 92-Time series spectrum estimation. In: Biomedical Computer Programs, X-Series Supplement, Vol. 3, p. 198. (University of California Press, Berkeley, 1969).

18. Dumermuth, G.: Electronic data processing in pediatric EEG. Neuropädiatrie, 2: 349 (1971).

19. Dumermuth, G., AND Flühler, H.: Some modern aspects in numerical spectrum analysis of multichannel electroencephalographic data. Med. Biol. Eng., 5: 319 (1967).

20. Feinberg, I., Braun, M., and Schulman, E.: EEG sleep patterns in mental retardation. Electroencephalogr. Clin. Neurophysiol., 27: 128 (1969).

21. Fisch, R. O., Torres, F., Gravem, H. J., Greenwood, C. S., And Anderson, J. A.: Twelve years of clinical experience with phenylketonuria: A statistical evaluation of symptoms, growth, mental development, electroencephalographic records, serum phenylalanine levels, and results of dietary management. Neurology, 19: 659 (1969).

22. Gerstl, B., Malamud, N., Eng, L. F., and Hayman, R. B.: Lipid alterations in human brains in phenylketonuria. Neurology, 17:51 (1967).

23. Gibbs, E. L., ANd Gibbs, F. A.: Extreme spindles: Correlation of electroencephalographic sleep pattern with mental retardation. Science, 138: 1106 (1962).

24. Glässer, A., and Mantegazzini, P.: Action of 5-hydroxytryptamine and 5-hydroxytryptophan on the cortical electrical activity of the midpontine pretrigeminal preparation of the cat with and without mesencephalic hemisection. Arch. Ital. Biol., 98: 351 (1960).

25. Gross, H. P., and Schulte, F. J.: Über vermehrte Spindelaktivität im Schlaf-EEG bei Kindern mit Phenylketonuria. $\mathrm{Z}$. Kinderheilk., 105: 324 (1969)

26. Horner, F. A., and Streamer, C. W.: Effect of a phenylalanine-restricted diet on patients with phenylketonuria. $J$. Amer. Med. Ass., 161: 1628 (1956).

27. Hsı, D. Y. Y.: Phenylketonuria 1967. Develop. Med. Child Neurol., 9: 531 (1967).

28. Hsia, D. Y. Y., Nishimura, K., ANd Brenchley, Y.: Mechanisms for the decrease of brain serotonin. Nature, 200:578 (1963).

29. Huang, I., AND Hsia, D. Y. Y.: Studies on inhibition of 5-hydroxytryptophan decarboxylase by phenylalanine metabolites. Proc. Soc. Exp. Biol. Med., 112: 81 (1963).

30. Hudson, F. P., Mordaunt, V. L., And Leahy, J.: Evaluation of treatment begun in first three months of life in 184 cases of phenylketonuria. Arch. Dis. Childhood, 45: 5 (1970).

31. Jouvet, M.: Mechanisms of the states of sleep: A neuropharmacological approach. In: S. S. Kety, E. V. Evarts, and H. L. Williams: Sleep and Altered States of Consciousness, p. 86. (Williams \& Wilkins, Baltimore, 1967).

32. Jouver, M.: Biogenic amines and the states of sleep. Science, 163: $32(1969)$

33. Jouver, M.: Neurohumoral basis of sleep. In: L. Madow and L. H. Snow: The Psychodynamic Implications of the Physiological Studies on Dreams, p. 3. (Charles C Thomas, Publisher, Springfield, Ill., 1970).

34. Kaiser, S., AND Bickel, H.: Psychological and developmental evaluation of phenylketonuric patients treated with a phen- ylalanine-restricted diet. In: H. Bickel, F. P. Hudson, and L. I. Woolf: Phenylketonuria, p. 263. (Georg Thieme Verlag, Stuttgart, 1971).

35. Kellaway, P., and Fox, B. J.: Électroencephalographic diagnosis of cerebral pathology in infants during sleep. J. Pediat., 41: 262 (1952).

36. Kleiner, B., Flühler, H., Huber, P. J., and Dumermuth, G.: Spectrum analysis of the electroencephalogram. Comp. Progr. Biomed., 1: 183 (1970).

37. Koklla, W. P.: Serotonin oder Somnotonin? Schweiz. Med. Wschr., 100: 357 (1970).

38. Koella, W. P., Feldstein, A., and Czicman, J. S.: The effect of parachlorophenylalanine on the sleep of cats. Electroencephalogr. Clin. Neurophysiol., 25: 481 (1968).

39. KüNKEx, H.: Die Periodik der paroxysmalen Dysrhythmie im Elektroencephalogramm. (Georg Thieme Verlagy Stuttgart, 1969).

40. Ledebur, I. X., And Tisset, R.: Modification de l'activité électrique cérébrale du lapin sous l'effet de micro-injections de précurseurs des monoamines dans les structures somnogènes bulbaires et pontiques. Electroencephalogr. Clin. Neurophysiol., 20: 370 (1966).

41. Lenard, H. G.: The development of sleep spindles in the EEG during the first two years of life. Neuropädiatrie, 1: 264 (1970).

42. Lenard, H. G., Bell, E. F., and Schulte, F. J.: Thyroid hormone and the development of bioelectric brain activity (in preparation).

43. Low, N. L., Bosma, J. F., And Armstrong, M. D.: Studies on phenylketonuria. VI. EEG studies in phenylketonuria. Amer. Med. Ass. Arch. Neurol. Psychiat., 77: 359 (1957).

44. LÜTCKE, A., AND BICKEL, H.: Hirnelektrische Untersuchungen bei der Phenylketonurie. Monatsschr. Kinderheilk., 116: 301 (1968).

45. Malamud, N.: Neuropathology of phenylketonuria. J. Neuropath. Exp. Neuro1., 25: 254 (1966).

46. Mandelx, A. J., Spooner, C. E., and Brunex, D.: Whither the "sleep transmitter." Biol. Psychiat., 1: 13 (1969).

47. Matsumoto, J., AND Jouver, M.: Effects de réserpine, DOPA et 5-HTP sur les deux états de sommeils. C. R. Soc. Biol. (Paris), 158: 2137 (1964).

48. Menkes, J. H.: The pathogenesis of mental retardation in phenylketonuria and other inborn errors of amino acid metabolism. Pediatrics, 39: 297 (1967).

49. Metcalf, D. R.: Sleep spindle ontogenesis. Neuropädiatrie, I: 428 (1970).

50. Nanler, H. L., ANd Hsia, D. Y. Y.: Epinephrine metabolism in phenylketonuria. Proc. Soc. Exp. Biol. Med., 107: 721 (196I).

5l. Osterholm, J. L., AND Bell, J.: Experimental effects of free serotonin on the brain and its relation to brain injury. Part 1: The neurological consequences of intracerebral serotonin injections. J. Neurosurg., 31: 408 (1969).

52. Pare, C. M. B., Sandler, M., and Stacey, R. S.: Decreased 5-hydroxytryptophan decarboxylase activity in phenylketonuria. Lancet, ii: 1099 (1958).

53. Parmelee, A. H., Schulte, F. J., Akiyama, Y., Wenner, W. H., Schultz, M. A., AND STERn, E.: Maturation of EEG activity during sleep in premature infants. Electroencephalogr. Clin. Neurophysiol., 24: 319 (1968). 
54. Petre-Quadens, O., And Jouver, M.: Paradoxical slecp and dreaming in the mentally retarded. J. Neurol. Sci., 3: 608 (1966).

55. Poley, J. R., and Dumermuth, G.: EEG-findings in patients with phenylketonuria before and during treatment with a low-phenylalanine diet and in patients with some other inborn errors of amino acid metabolism. In: K. S. Holt and V. P. Coffey: Some Recent Advances in Inborn Errors of Mctabolism, p. 61. (E. \& S. Livingstone, Ltd., London, 1968).

56. Poser, C. M., AND VAN Bogaert, L.: Neuropathologic observations in phenylketonuria. Brain, 82: 1 (1959).

57. Rothballer, A. B.: The eflect of phenylephrine, methamphetamine, cocaine, and serotonin upon the adrenaline sensitive component of the reticular activating system. Electroencephalogr. Clin. Neurophysiol., 9: 409 (1957).

58. Schulte, F. J., ANd BelL, E. F.: Bioelectric brain development: An atlas of EEG power spectra in infants and young children. Neuropädiatrie, 4: 30 (1973).

59. Schultz, M. A., Schulte, F. J., Akiyama, Y., and Parmelee, A. H.: Development of electroencephalographic sleep phenomena in hypothyroid infants. Electroencephalogr. Clin. Neurophysiol., 25: 351 (1968).

60. Spooner, C. E., and Winters, W. D.: The influence of centrally active amine induced blood pressure changes on the electroencephalogram and behavior. Int. J. Neuropharmacol., 6: 109 (1967).

61. TAshran, R. E.: Inhibition of brain glutamic acid decarboxylase by phenylalanine, valine, and leucine derivatives: A suggestion concerning the etiology of the neurological defect in phenylketonuria and branched-chain ketonuria. Metabolism, 10: 393 (1961).

62. Tu, J., and Partingron, M. W.: 5-Hydroxyindole levels in the blood and CSF in Down's syndrome, phenylketonuria and severe mental retardation. Develop. Med. Child Neurol., 14: 457 (1972).

63. WALTER, D. O.: Spectral analysis for electroencephalograms: Mathematical determination of neurophysiological relationships from records of limited duration. Exp. Neurol., 8: 155 (1963).

64. WAlter, D. O.: On units and dimensions for reporting spec- tral intensities. Electroencephalogr. Clin. Neurophysiol., 24: 486 (1968).

65. WALteR, D. O., AND AdEY, W. R.: Analysis of brain-wave gencrators as multiple statistical time series. I.E.E.E. Trans. Biomed. Eng., BME-12: 8 (1965).

66. WEIL-MALHERBRE, H.: Blood adrenaline and intelligence. In: H. Waelsch: Biochemistry of the Developing Nervous System. (Academic Press, New York, 1955).

67. Woolf, L. J., Griffiths, R., AND MoncriefF, A.: Treatment of phenylketonuria with a diet low in phenylalanine. Brit. Med. J., 1: 57 (1955).

68. Wratt, R. J., Engelman, K., Kupfer, D. J., Scott, J., SJOERDSMA, A., AND SNYDER, F.: Effect of parachlorophenylalanine on sleep in man. Electroencephalogr. Clin. Neurophysiol., 27: 529 (1969)

69. Wyatt, R. J., Zarcone, V., Engelman, K., Dement, W. C., SNYDER, F., AND SJOERDSMA, A.: 5-Hydroxytryptophan and human sleep. Electroencephalogx. Clin. Neurophysiol., 30:505 (I971).

70. Yamaguchi, N., Ling, G. M., and Marczynski, T. J.: The effects of chemical stimulation of the preoptic region, nucleus centralis medialis, or brain stem reticular formation with regard to sleep and wakefulness. Recent Advan. Biol. Psychiat., 6: 9 (1963).

71. Informed consent was obtained from the parents of each subject.

72. The assistance of Georg Grzemba is appreciated in writing the program for the computation of spindle peak power.

73. The amino acid determinations were done in the laboratory of our metabolic unit of Dr. W. von Berg who also supervised the treatment of all patients.

74. This work was supported by grants from the Deutsche Forschungsgemeinschaft, SFB 33. Computing assistance was obtained from the Health Science Computing Facility, University of California, Los Angeles, sponsored by National Institutes of Health Special Research Resources Grant RR 3.

75. Requests for reprints should be addressed to: F. J. SchulTE, M.D., Universitäts-Kinderklinik, Humboldtallee 38, 34 Göttingen, West Germany.

76. Accepted for publication January 24, 1973. 